\title{
Associação entre qualidade de sementes e rendimento de grãos em cultivares de feijão
}

\author{
Luan Tiago dos Santos CARBONARI ${ }^{1}$, Paulo Henrique CERUT'TI ${ }^{1}$, Pedro Antonio SCHWARZER ${ }^{1}$, \\ Anne Tietien MUNIZ1 ${ }^{1}$, Arthur Ribeiro RODRIGUES ${ }^{1}$ \\ ${ }^{1}$ Universidade do Estado de Santa Catarina, Lages, SC, Brasil. \\ *E-mail: paulohcerutti@gmail.com \\ (Orcid: 0000-0002-7797-5194; 0000-0001-6664-8449; 0000-0003-0812-6313; 0000-0001-8146-2829; 0000-0002-4401-3407)
}

\begin{abstract}
Recebido em 03/12/2020; Aceito em 02/06/2021; Publicado em 07/06/2021.
RESUMO: O cultivo de feijão apresenta elevada relevância em âmbito nacional. Além do rendimento de grãos, demais caracteres agronômicos associados são importantes na definição do potencial produtivo de um cultivar. Desse modo, o objetivo do trabalho foi avaliar a associação de características da qualidade de sementes com o rendimento de grãos em cultivares de feijão. Os experimentos foram executados em delineamento inteiramente casualizado e blocos ao acaso, ambos com quatro repetições, utilizando dez cultivares de feijão. As características avaliadas foram: rendimento de grãos $\left(\mathrm{kg} \mathrm{ha}^{-1}\right)$, número de plântulas normais e anormais, comprimento de plântula $(\mathrm{cm})$, comprimento de raiz $(\mathrm{cm})$, comprimento de parte aérea $(\mathrm{cm})$, massa fresca e seca de plântulas (g), e de massa fresca e seca cotilédones (g). A análise de componentes principais captou uma variação percentual nos dois eixos iniciais de 67,40 para variáveis, e 99,15 para os cultivares. As variáveis rendimento de grãos, massa seca de cotilédones e massa fresca de cotilédones relacionaram-se positivamente, com forte associação. A variável com maior contribuição para a discriminação dos cultivares foi o rendimento de grãos. O comprimento de plântulas, plântulas anormais e plântulas normais apresentaram menores contribuições e podem ser utilizadas complementarmente na discriminação de genótipos.
\end{abstract}

Palavras-chave: Phaseolus vulgaris L.; Potencial produtivo; PCA.

\section{Association between seed quality traits and grain yield in bean cultivars}

\begin{abstract}
The bean cultivation is highly relevant nationally. In addition to the grain yield trait, many agronomic characters are important in defining the productive potential of a bean cultivar. Thus, the objective of this work was to evaluate the association of characteristics of seed quality with grain yield in bean cultivars. The experiments were carried out in a completely randomized design and randomized blocks, both with four replications, using ten bean cultivars. The evaluated traits were grain yield $\left(\mathrm{kg} \mathrm{ha}^{-1}\right)$, number of normal and abnormal seedlings, seedling length $(\mathrm{cm})$, root length $(\mathrm{cm})$, shoot length $(\mathrm{cm})$, fresh and dry seedling mass $(\mathrm{g})$ and cotyledon fresh dry mass $(\mathrm{g})$. The principal component analysis captured a percentage change in the two initial axes of 67.40 for variables, and 99.15 for cultivars. The variables grain yield, cotyledon dry mass and cotyledon fresh mass were positively related, with a strong association. The variable with the greatest contribution to the discrimination of cultivars was grain yield. The seedling length, abnormal seedlings and normal seedlings showed less contributions, and can be used complementarily to discriminate genotypes.
\end{abstract}

Keywords: Phaseolus vulgaris L.; Productive potential; PCA.

\section{INTRODUÇÃO}

O cultivo de feijão (Phaseolus vulgaris L.), apresenta elevada importância principalmente na América do Sul e no continente Africano. Essa leguminosa tem seu consumo vinculado a excelente qualidade proteica presente em seus grãos. Em razão desse teor proteico e demais efeitos benéficos ao ser humano, o feijão é considerado um alimento funcional (CAROVIC-STANKO et al., 2017). Com base nessas características o brasileiro consome em média 17 a 20 $\mathrm{kg}$ de feijão por habitante no ano (SOUZA; WANDER, 2014).

Atualmente essa cultura é cultivada em até três safras, com sistemas de produção diversificados. Esses sistemas englobam desde o cultivo em pequena escala (com índole inteiramente familiar), até sistemas altamente tecnificados (com uso de agricultura de precisão e irrigação), praticado preponderantemente no cultivo de terceira safra (SOUZA;
WANDER, 2014). Para atender as necessidades produtivas e de consumidores, torna-se essencial o desenvolvimento de cultivares de feijão melhoradas geneticamente. Contudo, em muitas situações o máximo potencial produtivo de um cultivar não é obtido. Este fato deriva da expressão fenotípica das principais características de interesse agronômico serem governadas por muitos genes e consequentemente sofrerem uma forte influência do ambiente. De modo geral, o valor fenotípico é advindo de um efeito genético intrínseco ao cultivar, somado a um efeito ambiental e da interação genótipo ambiente (ALLARD, 1971). Com isso, visando altos níveis produtivos, é crucial a escolha de um cultivar que demonstre boa produtividade e adaptação aos distintos ambientes de cultivo.

Geralmente cultivares com alta produtividade apresentam elevada expressão fenotípica de caracteres 
adaptativos, como: i) número de racemos com legumes por planta; ii) número de legumes por planta; iii) número de sementes por legume e iv) altura de inserção do primeiro legume, descritos por IPGRI (2001). Contudo, objetivando altas produtividades na cultura é necessário conjuntamente a esses caracteres, visar uma implantação da lavoura adequada, com um estante correto de plantas e um fechamento rápido de entrelinhas. Este fato, pode diminuir a competição de plantas daninhas com a cultura e favorecer os tratos culturais. Com essa finalidade, a utilização de sementes de alta qualidade pode ser um diferencial no cultivo, principalmente quando a implantação da lavoura ocorre em ambientes submetidos a condições não ideais, como estresse hídrico ou nutricional (DÖRR et al., 2017; PINHEIRO et al., 2019).

No entanto, o cenário nacional de produção de feijão, apresenta baixa utilização de sementes certificadas dos cultivares melhorados (BERTOLIN et al., 2011). Neste sentido, a realização das análises de sementes para diferentes caracteres em âmbito laboratorial, conjuntamente a avaliação de rendimento de grãos a campo, é essencial para estabelecer relações entre estas características na cultura do feijão. Assim, o objetivo do trabalho foi verificar a associação de características da qualidade de sementes com o rendimento de grãos em cultivares de feijão.

\section{MATERIAL E MÉTODOS}

O trabalho foi composto por dez tratamentos correspondentes às cultivares comerciais de feijão, BRS Campeiro ${ }^{\circledR}$, BRS Esplendor ${ }^{\circledR}$, BRS Esteio ${ }^{\circledR}$, BRS Perola ${ }^{\circledR}$, IAC Imperador ${ }^{\circledR}$, IPR Campos Gerais ${ }^{\circledR}$, IPR Tuiuiú ${ }^{\circledR}$, IPR Uirapuru ${ }^{\circledR}$, SCS204 Predileto ${ }^{\circledR}$, SCS205 Riqueza ${ }^{\circledR}$. As variáveis avaliadas foram: rendimento de grãos $\left(\mathrm{kg} \mathrm{ha}^{-1}\right)$, número de plântulas normais, número de plântulas anormais, comprimento de plântula $(\mathrm{cm})$, comprimento de raiz $(\mathrm{cm})$, comprimento de parte aérea $(\mathrm{cm})$, massa fresca de plântulas (g), massa fresca de cotilédones (g), massa seca de plântulas (g) e massa seca de cotilédones $(\mathrm{g})$. A variável rendimento de grãos foi avaliada no município de Lages. O solo da área em questão é classificado como Cambissolo Húmico Alumínico Léptico, com horizonte A moderado, textura argilosa e relevo ondulado.

O delineamento experimental utilizado no ensaio a campo foi o de blocos ao acaso com quatro repetições. A unidade experimental foi composta por quatro linhas de quatro metros, com espaçamento uniforme entre linhas de $0,45 \mathrm{~m}$. A densidade de semeadura foi de 15 sementes por metro linear, com população final de 200.000 plantas ha $^{-1}$. A área útil de cada unidade experimental foi composta por duas linhas centrais, excluindo as duas externas, visando minimizar os efeitos de bordadura. As adubações de semeadura e de cobertura foram realizadas com base na confecção e interpretação de análise de solo, observando-se as recomendações técnicas para cultura (CQFS-RS/SC, 2016).

As análises fisiológicas da qualidade de sementes foram realizadas utilizando delineamento inteiramente casualizado. O número de plântulas normais foi determinado com quatro subamostras de 50 sementes por tratamento, acondicionadas em rolos de papel Germitest ${ }^{\circledR}$, umedecidos com água destilada e deionizada a uma equivalência de 2,5 vezes seu peso seco. Os rolos de papel foram mantidos em incubadora BOD (Demanda Bioquímica de Oxigênio), regulada a temperatura de $25^{\circ} \mathrm{C}$, com fotoperíodo de 12 horas. As contagens foram realizadas no quinto e nono dia após início do experimento. Conjuntamente a variável plântulas normais, determinou-se a quantidade de plântulas anormais, seguindo padrões das Regras de Análises de Sementes (BRASIL, 2009).

Para a determinação do comprimento de plântulas também foram utilizadas quatro sub-amostras, com 20 sementes, dispostas sobre duas linhas traçadas no terço superior do papel Germitest ${ }^{\circledR}$, no sentido longitudinal, umedecido com 2,5 vezes o peso seco com água destilada e deionizada. Os rolos confeccionados foram mantidos na vertical, em $\mathrm{BOD}$ regulada à temperatura de $25^{\circ} \mathrm{C}$, com fotoperíodo alternado de 12 horas, por cinco dias. Posteriormente, com auxílio de um paquímetro determinouse o comprimento $(\mathrm{cm})$ de 10 plântulas, obtidas ao acaso (NAKAGAWA, 1994). O comprimento de raiz (cm) foi obtido paralelamente ao de plântula, sendo mensurado a partir da inserção do sistema radicular na plântula. $O$ comprimento da parte aérea $(\mathrm{cm})$, foi obtido por diferença entre o comprimento de raiz e comprimento de plântula.

A massa fresca de plântulas e cotilédones foi estabelecida posteriormente as determinações de comprimentos. As 10 plântulas de cada subamostra foram retiradas do substrato, os cotilédones foram separados de eixos embrionários, ambos sendo pesados. As plântulas e cotilédones foram submetidos a secagem em estufa com circulação de ar forçado, regulada a $80^{\circ} \mathrm{C}$, durante 24 horas. Após este período, foi determinada a matéria seca total das 10 plântulas normais de cada repetição. A massa obtida foi dividida pelo número de plântulas utilizadas, resultando na massa média de matéria seca por plântula, em gramas (NAKAGAWA, 1994).

As informações coletadas foram submetidas a transformação dos dados, visto a grande diferença na magnitude das escalas ordinárias. Essa etapa foi realizada extraindo o logaritmo normal da base de dados, com finalidade de evitar superestimativas ou subestimar o peso de uma variável estudada, por questões relacionadas às diferenças de escala de medida. Posteriormente foi realizada a análise multivariada, das dez variáveis respostas e dos dez cultivares. A análise dos componentes principais foi calculada por meio da matriz n x p, para as quais " $\mathrm{n}$ " é o número de variáveis (variáveis=10) e "p" são as quatro repetições dos 10 genótipos; posteriormente transpondo a matriz, com " $\mathrm{n}$ " sendo genótipos e "p" variáveis.

Com as matrizes de correlação foram calculados os autovalores (valores representativos da variabilidade retida por cada novo componente) e autovetores (combinação linear dos parâmetros avaliados), sendo aplicados aos gráficos de duas dimensões (biplots). Todos os procedimentos foram realizados utilizando o software R (R CORE TEAM, 2018), com base no pacote 'MVar.pt' versão 2.1.2 (OSSANI \& CIRRILO, 2020).

\section{RESULTADOS}

A análise de componentes principais (PCA) foi utilizada para determinar as associações das variáveis analisadas e cultivares. Para as variáveis, os dois componentes principais acumulam uma porcentagem da variação de $67,40 \%$. O CP1 apresentou $41,19 \%$ de variação explicada entre as variáveis, enquanto o CP2 26,21\%, ocorrendo uma redução percentual de $14,98 \%$ de variação explicada. Na relação entre cultivares os dois componentes iniciais acumulam cerca de 99,15\% da variância, com o CP1 retendo grande variação $(98,78 \%)$ e CP2 apenas 0,37\% (Tabela 1). 
Tabela 1. Componentes principais obtidos com análise de dez variáveis em dez cultivares de feijão, com as respectivas porcentagens de variação explicada (P.V.E) e acumulada (P.V.A) para os dez componentes.

Table 1. Main components obtained with analysis of ten variables in ten bean cultivars, with the respective percentage of explained (P.V.E) and accumulated (P.V.A) variation for the ten components.

\begin{tabular}{|c|c|c|c|c|}
\hline \multirow[b]{2}{*}{ Componentes } & \multicolumn{2}{|c|}{----- Variáveis ----- } & \multicolumn{2}{|c|}{----- Cultivares ----- } \\
\hline & $\begin{array}{c}\text { P.V.E. } \\
(\%)\end{array}$ & $\begin{array}{c}\text { P.V.E. } \\
(\%)\end{array}$ & $\begin{array}{c}\text { P.V.E. } \\
(\%)\end{array}$ & $\begin{array}{c}\text { P.V.E. } \\
(\%)\end{array}$ \\
\hline CP1 & 41,19 & 41,19 & 98,78 & 98,78 \\
\hline CP2 & 26,21 & 67,40 & 0,37 & 99,15 \\
\hline $\mathrm{CP} 3$ & 12,62 & 80,02 & 0,26 & 99,42 \\
\hline CP4 & 11,43 & 91,45 & 0,20 & 99,62 \\
\hline CP5 & 4,47 & 95,93 & 0,12 & 99,75 \\
\hline $\mathrm{CP} 6$ & 2,15 & 98,08 & 0,08 & 99,83 \\
\hline $\mathrm{CP} 7$ & 1,05 & 99,14 & 0,05 & 99,89 \\
\hline CP8 & 0,49 & 99,63 & 0,03 & 99,93 \\
\hline $\mathrm{CP} 9$ & 0,34 & 99,98 & 0,03 & 99,97 \\
\hline CP10 & 0,02 & 100 & 0,02 & 100 \\
\hline
\end{tabular}

Para a representação da análise dos componentes principais utilizou-se o gráfico de duas dimensões (biplot). A projeção nos resultados dos componentes principais com CP1 e CP2 (Figura 1), identificou correlações positivas entre as variáveis, formando um agrupamento entre comprimento de plântulas (CP), comprimento raiz (CPR), comprimento de parte aérea (CPA), massa fresca de plântulas (MFP) e massa seca de plântulas (MSP). A associação observada por estas variáveis é compreensível, pois apresentam um desenvolvimento conjunto no momento de formação de plântulas. No entanto estas variáveis não apresentaram associação com o rendimento de grãos (REND), número de plântulas normais $(\mathrm{PN})$ e plântulas anormais (PA). As variáveis rendimento de grãos (REND), massa seca de cotilédone (MSC) e massa fresca de cotilédone (MFC) relacionaram-se positivamente, com forte associação (Figura 1).

A análise dos componentes principais (Figura 2), com cultivares corroborando para os vetores, indicam dois agrupamentos principais. Os cultivares Campos Gerais (Campos), e Imperador apresentam uma dissimilaridade dos demais, baseado nas variáveis levadas em consideração. De maneira geral, como um todo os cultivares, apresentam forte associação com a variável rendimento de grãos, indicando uma maior contribuição desta no momento na plotagem dos auto vetores. Além da variável rendimento de grãos, o comprimento de plântulas (CP), plântulas anormais (PA) e plântulas normais $(\mathrm{PN})$ contribuíram em menor escala para a discriminação dos cultivares avaliados (Figura 2). Conforme observado nos biplots (Figuras 1 e 2), é possível o descarte categórico de algumas variáveis visando a discriminação dos genótipos em estudo (MFC, MSC, MSP MFP, CPR e CPA). Este fato é decorrente destas apresentarem pouca ou nenhuma contribuição para a discriminação dos genótipos avaliados.

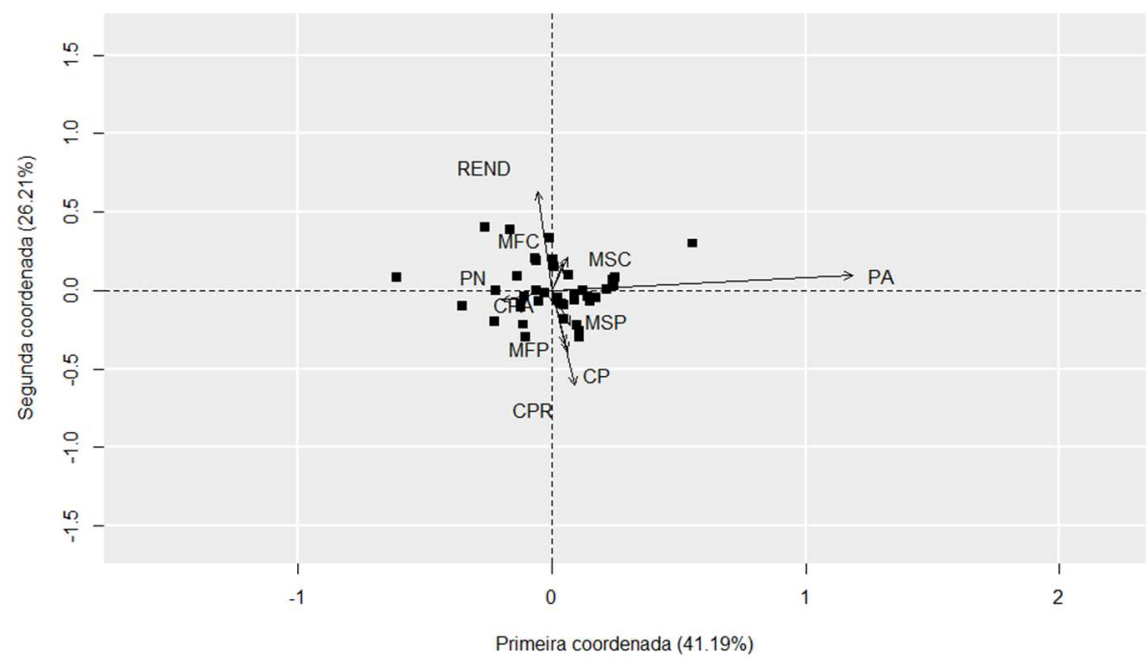

Figura 1. Representação (Biplot) da análise de componentes principais, valorizando as variáveis comprimento de plântula $(\mathrm{CP})$, massa seca de plântula (MSP), massa seca de cotilédone (MSC), comprimento de parte aérea (CPA), plântulas normais (PN), Rendimento (REND), parte aérea (PA), massa fresca de plântula (MFP), comprimento raiz (CPR) e massa fresca de cotilédone (MFC), em função das primeiras e segundas coordenadas dos eixos.

Figure 1. Representation (Biplot) of the principal component analysis, valuing the variables seedling length (CP), seedling dry mass (MSP), cotyledon dry mass (MSC), shoot length (CPA), normal seedlings (PN), Yield (REND), aerial part (PA), fresh seedling mass (MFP), root length (CPR) and fresh cotyledon mass (MFC), depending on the first and second axes coordinates.

\section{DISCUSSÃO}

Conforme observado no trabalho, os autores TobarTosse et al. (2014) também destacam que os dois componentes principais foram adequados para explicar a variância contidas nas variáveis consideradas. De acordo com Cruz; Regazzi (1994), um dos objetivos do uso dos componentes principais em estudo sobre a divergência genética é avaliar a dissimilaridade dos genótipos em gráficos de dispersão, com a utilização dos primeiros componentes como eixos de referência. Este procedimento é satisfatório quando os dois primeiros componentes utilizados como eixo do sistema cartesiano representam uma fração considerável da variação total, normalmente citada como acima de 70 a $80 \%$.

De modo geral a PCA busca explicar a estrutura das variâncias e covariâncias por meio de combinações lineares 
das variáveis originais, visando um agrupamento destas, pois a relação destas variáveis apresenta extrema relevância no campo de pesquisa biológica. Desse modo, justifica-se a linearização das variáveis, extraindo-se o logaritmo base 10 destas, em razão da diferença de escalas, por exemplo: i) rendimento em $\mathrm{kg} \mathrm{ha} \mathrm{h}^{-1}$; ii) plântulas normais expressas em porcentagem; iii) massas em gramas (g). As maiores porcentagens de variância observadas nos primeiros eixos são advindas da independência das combinações lineares, consequentemente os eixos iniciais captam proporções com maior relevância, em comparação aos eixos sucessivos (CRUZ, 1990).

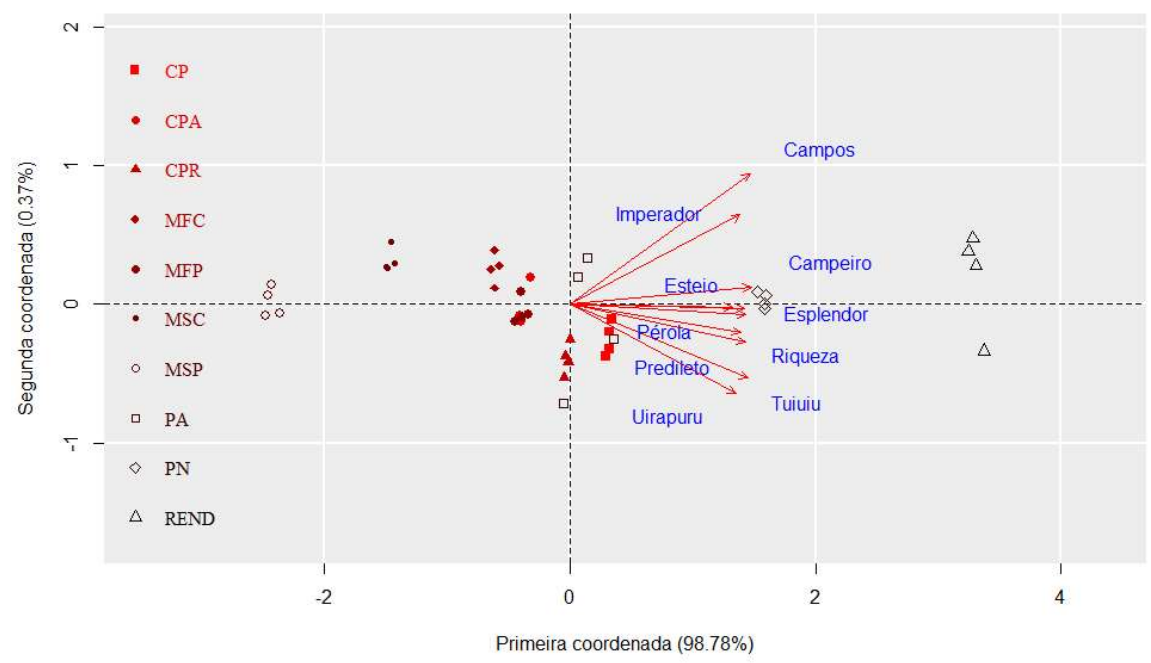

Figura 2. Representação (Biplot) da análise de componentes principais valorizando os cultivares, na primeira e segunda coordenada, com base nas variáveis: comprimento de plântula (CP), massa seca de plântula (MSP), massa seca de cotilédone (MSC), comprimento de parte aérea (CPA), plântulas normais (PN), Rendimento (REND), parte aérea (PA), massa fresca de plântula (MFP), comprimento raiz (CPR) e massa fresca de cotilédone (MFC).

Figure 2. Representation (Biplot) of the principal component analysis valuing the cultivars, in the first and second coordinates, based on the variables: seedling length (CP), seedling dry mass (MSP), cotyledon dry mass (MSC), part length aerial (CPA), normal seedlings (PN), Yield (REND), aerial part (PA), fresh seedling mass (MFP), root length (CPR) and fresh cotyledon mass (MFC).

A falta de relação entre as variáveis de qualidade de sementes e rendimento de grãos possivelmente está associada a característica intrínseca dos testes utilizados. Estes visam a determinação da qualidade de sementes de forma indireta, visto que proporcionam condições favoráveis ao crescimento e desenvolvimento de sementes (BARBOSA et al., 2012; DOS SANTOS et al., 2019). Tais condições resultam em uma situação distinta a qual as sementes geralmente são submetidas a campo. Visando contornar essas condições, alguns testes diretos são utilizados na correção destes equívocos, como envelhecimento acelerado. Este teste busca simular nas sementes um período de armazenamento, onde se tem alta temperatura e alta umidade relativa, fazendo com que as sementes menos vigorosas sintam mais as condições adversas ofertadas e não condições adversas observadas a campo.

Dessa forma, uma melhor predição da qualidade das sementes a serem utilizadas na implantação da lavoura pode ser obtida com a utilização de testes de vigor adequados (MARCOS FILHO, 2015). Considerado crucial para o desenvolvimento das plântulas em condições adversas, o vigor das sementes em detrimento da qualidade fisiológica tem uma ampla discussão na literatura. Essa característica pode afetar o estabelecimento inicial das lavouras, influindo consideravelmente no acúmulo de matéria seca inicial das plântulas. Contudo este efeito tende a ser reduzido, com a evolução dos estádios fenológicos das culturas, praticamente desaparecendo no instante final.

Os autores TeKrony et al. (1989) e Khah et al. (1989), definem que as vantagens iniciais obtidas com a qualidade das sementes, apresenta redução quando é levado em consideração a competição entre plantas. Assim com os sucessivos estádios de crescimento e desenvolvimento, essa interferência obtida inicialmente, fica mais dependente das relações da interação genótipo $\mathrm{x}$ ambiente, tornando as plantas assim, independentes da qualidade fisiológica das sementes. Ressalta-se que este fato tem restrição as condições de cultivo, quando levado em consideração situações que não há redução do estande de plântulas, esta associação de qualidade de sementes e rendimento é nula (MARCOS FILHO, 1999).

Outro fato relevante, como foi comentado acima e demonstrado na Figura 2, um maior rendimento de grãos nem sempre vem associado a melhor qualidade fisiológica de sementes, pois como a maioria dos cultivares comerciais cultivados apresentam hábito de crescimento do tipo 2 ou 3 (sendo a maioria intermediário entre esses) e quando estes apresentam um bom desenvolvimento tendem mais para o tipo 3, prostrando suas vagens no solo e assim diminuindo a qualidade da semente colhida.

As associações das variáveis rendimento de grãos, massa seca de cotilédone e massa fresca de cotilédone podem ter como base o conteúdo de reservas dos cotilédones a serem utilizados para a formação de plântulas, através dos mecanismos bioquímicos que atuam no processo de formação destas. Pois, conjuntos de enzimas como "Amilases" e "Fitases" hidrolisam os componentes de reservas "amido" e "fitato", presentes nos tecidos cotiledonares. Essa hidrolise é complementada com a translocação destas substâncias para o eixo de crescimento das plântulas. Quando bem fundamentado esse processo, e com baixa atividade de espécies reativas de oxigênio acumuladas pelo estresse oxidativo, resultante do processo de respiração e condições adversas, a capacidade de um 
estabelecimento rápido e uniforme das plantas é consolidada (MARCOS FILHO, 2015).

Como já explanado, quando no momento de implantação da cultura, as condições de ambiente forem favoráveis, (sem adversidades, como estresse hídrico, baixas ou altas temperaturas), a produtividade de grãos consequentemente tem baixa associação as métricas de qualidade de sementes, exceto germinação, visto esta ser fundamental para a população desejada de plantas. Em complemento, quando as condições na implantação da lavoura forem desfavoráveis, a utilização de genótipos melhorados, levando em consideração essas características, podem apresentar grande relevância no cenário produtivo nacional (MAMBRIN et al., 2015). Com isso, atualmente a pesquisa tem dedicado esforços para desenvolver e identificar cultivares com maior tolerância aos estresses abióticos (TEXEIRA et al., 2008, SUÁREZ et al., 2020). Sendo assim, a avaliação ampla de caracteres para os estudos de divergência genética é fundamental, na realização de screenings das características mais importantes para este fim, levando em consideração o potencial de impacto econômico nos sistemas de produção.

Para este fim, a técnica de análise de componentes principais vem sendo utilizada com frequência para a caracterização de bancos de germoplasma (RODRIGUES et al., 2002; BARBIERI et al., 2005). A frequente utilização é devido a mesma possibilitar a identificação de características importantes a serem avaliadas por meio de estudos prévios da caracterização e discriminação da variabilidade existente nos bancos de germoplasma, bem como na indicação de caracteres com maior relevância com base nos objetivos do programa (PEREIRA, 1989; SILVEIRA et al., 2019).

Conforme observado, a forte associação dos cultivares com a variável rendimento de grãos e em menores intensidades com comprimento de plântulas, plântulas anormais e plântulas normais, demonstra maior relevância para estas características. Possibilitando a identificação de caracteres que demonstrem capacidade de representar a variação total obtida no conjunto de dados, com a finalidade apresentada neste estudo. Neste sentido estudos entre esses caracteres são fundamentais, buscando compreender a intercorrelação destes, podendo colaborar para a manutenção e expansão da produtividade desta cultura.

\section{CONCLUSÕES}

As variáveis de qualidade de sementes, massa seca de cotilédone e massa fresca de cotilédone apresentaram associação ao rendimento de grãos. A maior contribuição a variação dos cultivares foi obtida pelas variáveis rendimento de grãos, comprimento de plântulas, plântulas anormais e plântulas normais.

\section{REFERÊNCIAS}

ALLARD, R. W. Princípios do melhoramento genético de plantas. São Paulo: Edgard Blucher, 1971. 381p.

BARBIERI, R. L.; LEITE, D. L.; CHOER, E.; SINIGAGLIA, C. Divergência genética entre populações de cebola com base em marcadores morfológicos. Ciência Rural, Santa Maria, v. 35, n. 2, p. 303-308, 2005. https://doi.org/10.1590/S0103-84782005000200009

BARBOSA, F. R.; GONZAGA, A. C. de O. Informações técnicas para o cultivo do feijoeiro-comum na Região Central-Brasileira: 2012-2014. Santo Antônio de Goiás: Embrapa Arroz e Feijão, 2012. 247p. (Documentos, 272)

BERTOLIN, D. C.; SÁ, M. E.; MOREIRA, E. R. Parâmetros do teste de envelhecimento acelerado para determinação do vigor de sementes de feijão. Revista Brasileira de Sementes, Londrina, v. 33, n. 1, p. 104-112, 2011. DOI: https://doi.org/10.1590/S0101-31222011000100012

BRASIL. Ministério da Agricultura e Reforma Agrária. Regras para Análise de Sementes. Departamento Nacional de Defesa Vegetal, 2009. 395 p.

CAROVIĆ-STANKO, K.; LIBER, Z.; VIDAK, M.; BAREŠIĆ, A.; GRDIŠA, M.; LAZAREVIĆ, B.; ŠATOVIĆ, Z. Genetic diversity of Croatian common bean landraces. Frontiers in Plant Science, v. 8, p. 604, 2017. DOI: https://doi.org/10.3389/fpls.2017.00604

CQFS-RS/SC_Comissão de Química e Fertilidade do Solo RS/SC. Manual de calagem e adubação para os Estados do Rio Grande do Sul e de Santa Catarina. Rio de Janeiro: Sociedade Brasileira de Ciência do Solo. 2016. 376p.

CRUZ, C. D. Aplicação de algumas técnicas multivariadas no melhoramento de plantas. 1990. 188 f. Tese de Doutorado. Tese (Doutorado) - Escola Superior de Agricultura Luiz de Queiroz, Piracicaba. 1990.

CRUZ, C. D.; REGAZZI, A. J. Modelos biométricos aplicados ao melhoramento genético. Viçosa: UFVImprensa Universitária, 1994. 390p.

DÖRR, C. S.; KOCH, F.; RADKE, A. K.; MIGLIORINI, P.; EBERHARDT, P. E. R.; VAHL, L. C. Qualidade fisiológica de sementes de feijão tratadas com zinco. Revista de Ciências Agroveterinárias, Lages, v. 16, n. 4, p. 414-421, $2017 . \quad$ DOI: https://doi.org/10.5965/22381171164201741

DOS SANTOS, F. G.; SILVEIRA, E. R.; JAMHOUR, J. Atributos de qualidade de sementes salvas de feijão. Revista Técnico-Científica do CREA-PR, n. 22, p. 1-14, 2019. Disponível em: http://creaprw16.creapr.org.br/revista/Sistema/index.php/revista/article/vie $\mathrm{w} / 523$

IPGRI. Descritores para Phaseolus vulgaris. International Plant Genetic Resources Institute, Rome, 2001. 45p.

KHAH, E. M.; ROBERTS, E. H.; ELLIS, R. H. Effects of seed ageing on growth and yield of spring wheat at different plant-population densities. Field Crops Research, v. 20, n. 3, p. 175-190, 1989.

MAMBRIN, R. B.; RIBEIRO, N. D.; HENNING, L.; MERTZ, M.; HENNING, F. A.; BARKERT, K. A. Seleção de linhagens de feijão com base no padrão e na qualidade de sementes. Revista Caatinga, Mossoró, v. 28, n. 3, p. 147-156, 2015.

MARCOS FILHO, Júlio. Fisiologia de sementes de plantas cultivadas. ABRATES, Londrina, 2015. 660p.

MARCOS FILHO, Júlio. Testes de vigor: importância e utilização. Vigor de sementes: conceitos e testes. ABRATES, Londrina, 1999. cap.1, p.1-21.

NAKAGAWA, J. Testes de vigor baseados na avaliação das plântulas. In: VIEIRA, R. D.; CARVALHO, N. M. (Eds.). Testes de vigor em sementes. Jaboticabal: Funep, 1994. p. 49-85.

OSSANI, P. C.; CIRRILO, M. A. MVar.pt: Análise multivariada (brazilian portuguese). 2020. R package version 2.1.2. Disponível em: https://cran.rproject.org/web/packages/MVar.pt/index.html 
PEREIRA, A. V. Utilização de análise multivariada na caracterização de germoplasma de mandioca (Manihot esculenta Crantz). 180 f. 1989. Tese (Doutorado) - Universidade de São Paulo, Piracicaba, 1989.

PINHEIRO, R. D. A.; DUARTE, V. C. B.; BEVILAQUA, G. A. P.; ANTUNES, I. F. Efeito de preparados homeopáticos no vigor de sementes e desenvolvimento de plântulas de feijão. Revista de Ciências Agrárias, Lisboa, v. 42, n. 2, p. 81-90, 2019. DOI: https://doi.org/10.19084/rca.15209

R Core Team. A Language and Environment for Statistical Computing. R Foundation for Statistical Computing. Vienna, Austria, 2018.

RODRIGUES, L. S.; ANTUNES, I. F.; TEIXEIRA, M. G.; SILVA, J. B. da. Divergência genética entre cultivares locais e cultivares melhoradas de feijão. Pesquisa Agropecuária Brasileira, Brasília, v. 37, n. 9, p. 12751284, 2002. DOI: https://doi.org/10.1590/S0100204X2002000900011

SILVEIRA, D. C.; MACHADO, J. M.; FACCIOLI, M. W. F.; TOLFO, A. M.; EICH, C. Diversidade genética de acessos de feijão crioulo na região Noroeste do Rio Grande do Sul. Pesquisa Agropecuária Gaúcha, Porto Alegre, v. 25, n. 1/2, p. 133-146, 2019.

SOUZA, R. S.; WANDER, A. E. Aspectos econômicos da produção de feijão no Brasil. Revista de Política Agrícola, v. 23, n. 3, p. 43-54, 2014.

SUÁREZ, J. C.; POLANÍA, J. A.; CONTRERAS, A. T.; RODRÍGUEZ, L.; MACHADO, L.; ORDOÑEZ, C.; RAO, I. M. Adaptation of common bean lines to high temperature conditions: genotypic differences in phenological and agronomic performance. Euphytica, v. 216, n. 2, e28, 2020. DOI: https://doi.org/10.1007/s10681-020-2565-4

TEKRONY, D. M.; EGLI, D. B.; WICKHAM, D. A. Corn Seed Vigor Effect on No-Tillage Field Performance. I. Field Emergence. Crop science, v. 29, n. 6, p. 1523-1528, 1989.

TEXEIRA, L. R.; BRACCINI, A. de L. e; SPERANDIO, D.; SCAPIM, C. A.; SCHUSTER, I.; VIGANÓ, J. Avaliação de cultivares de soja quanto à tolerância ao estresse hídrico em substrato contendo polietileno glicol. Acta Scientiarum. Agronomy, v. 30, n. 2, p. 217-223, 2008. DOI: https://doi.org/10.4025/actasciagron.v30i2.1731

TOBAR-TOSSE, D. E.; CASTOLDI, R.; CANDIDO, W. D. S.; FERRAUDO, A. S.; CHARLO, H. C. D. O.; BRAZ, L. T. Caracterização de genótipos de sojahortaliça por análise de componentes principais. Ciência Rural, Santa Maria, v. 45, n. 7, p. 1214-1219, 2015. DOI: https://doi.org/10.1590/0103-8478cr20140597 